\section{Abordagem funcionalista da oração adjetiva: uma intervenção pedagógica no ensino fundamental}

Functional approach to adjective clause: a pedagogical intervention in elementary school

Edvaldo Balduino BISPO (UFRN) edbbispo@gmail.com

Lígia Maria da SILVA (UFRN) ligiamdsilva@gmail.com

Recebido em: 28 de abr. de 2020. Aceito em: 01 de jun. de 2020.
BISPO, Edvaldo Balduino; SILVA, Lígia Maria da. Abordagem funcionalista da oração adjetiva: uma intervenção pedagógica no ensino fundamental. Entrepalavras, Fortaleza, v. 10, n. 2, e1897, p. 1-21, maio-ago/2020. DOI: 10.22168/2237-6321-21897.

Resumo: Neste artigo, apresentamos e discutimos resultados da aplicação de uma proposta didática de abordagem funcionalista da oração adjetiva no Ensino Fundamental. Objetivamos contribuir para a melhoria do ensino desse tipo oracional, considerando textos autênticos produzidos em situações reais de interação e o respeito à diversidade de usos linguísticos. Por meio de uma pesquisa interventiva, de natureza qualitativointerpretativista, desenvolvemos sequência de aulas composta por quatro etapas. A intervenção ancorouse teórico-metodologicamente na Linguística Funcional norte-americana e em sua correlação com o ensino de Língua Portuguesa, notadamente em conformidade com as orientações curriculares nacionais. Os achados revelam que os alunos da turma participante apresentaram melhor compreensão do conteúdo em relação à turma de controle. Essa melhor compreensão relaciona-se, principalmente, a: i) diferentes modos de organização da adjetiva, ii) aspectos semânticos e discursivo-pragmáticos atinentes aos usos dessas orações e ao núcleo nominal a que elas se ligam e iii) distinção entre restritiva e explicativa. Os resultados também revelam a necessidade 
V. $10(2)$

$1-21$ maio-ago 2020 de ajustes devido à realidade das turmas e ao atendimento às bases teóricas que fundamentaram a intervenção. Tais ajustes incluem, por exemplo, o tempo destinado às atividades e a readequação de algumas questões dos exercícios.

Palavras-chave: Oração adjetiva. Linguística Funcional. Ensino de Língua Portuguesa.

Abstract: In this paper, we present and discuss the results of applying a didactic proposal for a functionalist approach to adjective clause in Elementary School. We aim to contribute to the improvement of teaching of adjective clause, considering authentic texts produced in real situations of interaction and respecting the diversity of linguistic usage. Through an interventional research, of a qualitative-interpretative nature, we developed a sequence of classes composed of four stages. The theoretical and methodological support is the North American Functional Linguistics and its correlation with Portuguese language teaching, notably in accordance with national curriculum guidelines. The findings reveal that the students in the participating class had understood the content better than that ones of the control class. This better understanding is mainly related to: i) different strategies of adjective clauses, ii) semantic and discursive-pragmatic aspects related to the uses of these clauses and the head noun to which they are linked and iii) distinction between restrictive and nonrestrictive adjective clause. The results also show the need for adjustments due to the reality of the classes and the attendance to the theoretical support. Such adjustments include the time allocated to activities and the readjustment of some exercise questions.

Keywords: Adjective clause. Functional Linguistics. Portuguese Language Teaching.

\section{Introdução}

É pauta constante o pleito de que sejam incorporadas, em sala de aula, práticas pedagógicas significativas a fim de que o aluno possa melhor associar o conhecimento sistematizado/formal escolar aos saberes que traz consigo. Quanto ao ensino de Língua Portuguesa, mais especificamente, destacamos a necessidade de pensar, efetivamente, em formas de tratar conteúdos gramaticais que não se circunscrevam à mera identificação de entidades e seus subtipos, à excessiva valorização de aspectos normativos e às regras de exceção. Esse tipo de procedimento, de caráter limitador, tem legado consequências negativas, a exemplo da visão equivocada do que seria o funcionamento da linguagem e, em consequência, um crescente desinteresse pelas aulas de Língua Portuguesa.

Conforme preveem os Parâmetros Curriculares Nacionais PCN (BRASIL, 1998), há duas décadas, e segundo a mais recente Base Nacional Comum Curricular - BNCC (BRASIL, 2018), os conteúdos gramaticais devem ser trabalhados de modo que propiciem aos alunos a análise e a reflexão linguística em situações reais de interação, ou seja, voltadas a práticas sociais situadas. Nessa direção, apresentamos e discutimos resultados de uma intervenção pedagógica desenvolvida 
com turma concluinte do Ensino Fundamental na disciplina de Língua Portuguesa. O trabalho fundamentou-se nos pressupostos da Linguística Funcional norte-americana e em sua correlação com o ensino de Língua Portuguesa, com base em Oliveira e Cezario (2007), Furtado da Cunha, Bispo e Silva (2014), Oliveira e Wilson (2015) e em orientações curriculares nacionais (BRASIL, 1998, 2018).

De modo específico, o nosso objeto de estudo é a oração subordinada adjetiva, cujo ensino, tradicionalmente, tem priorizado a identificação e a classificação das adjetivas, quando não se restringido unicamente a essas questões, correlacionado a oposição explicativa versus restritiva quase exclusivamente à presença/ausência de sinal de pontuação. Via de regra, a abordagem tradicional desse conteúdo é feita a partir de períodos desvinculados de uma situação de uso efetivo da língua. No entanto, esse tratamento dado às adjetivas parece não dar conta de diversos aspectos envolvidos nos usos desse tipo oracional, conforme atestam algumas pesquisas, a exemplo de Bispo (2007, 2009), Souza (2009) e Câmara (2015). Achados desses estudiosos têm revelado a importância de se considerarem fatores semânticos e discursivopragmáticos das orações adjetivas e do núcleo nominal a que elas se vinculam, bem como suas diferentes formas de organização, o que envolve estruturas canônicas e não canônicas. Para tanto, é fundamental flagrar o fenômeno em funcionamento.

Nessa direção, esta pesquisa objetiva contribuir para a melhoria do ensino da oração adjetiva, por meio de uma abordagem funcionalista conjugada a orientações curriculares oficiais. Para isso, elaboramos e aplicamos uma proposta didática e realizamos uma análise quali-quantitativa dos resultados.

O artigo está organizado, além da introdução, em quatro seções, que condensam, nesta ordem, o aporte teórico, os aspectos metodológicos, os resultados e discussão e as considerações finais.

\section{Funcionalismo e ensino}

Caracterizamos, nesta seção, a perspectiva teórica em que fundamentamos o trabalho empreendido, delineamos a abordagem do ensino de língua à luz dessa vertente teórica e a correlacionamos com diretrizes gerais para o ensino de Língua Portuguesa.

A Linguística Funcional norte-americana caracteriza-se por estudar a relação entre a estrutura gramatical das línguas e os diferentes 
V. $10(2)$

1-21

maio-ago

2020

contextos interacionais em que ela é utilizada. Assume o pressuposto básico de que a estrutura linguística resulta da função a que a língua serve nas diversas situações de interação verbal. Assim, a relação formafunção é o fio condutor que norteia os trabalhos desenvolvidos sob essa perspectiva teórica. Dessa premissa fundamental advém a ideia de que a língua deve ser vista como um sistema adaptativo (DU BOIS, 1985) utilizado para fins de comunicação. Ainda relacionadas a essa premissa estão a noção de que discurso e gramática interagem e se influenciam mutuamente, bem como a visão de que a gramática resulta da cristalização ou regularização de estratégias discursivas recorrentes (FURTADO DA CUNHA; COSTA; CEZARIO, 2015). Visto que fatores cognitivos, comunicativos e culturais coatuam na emergência, convencionalização e mudança do sistema linguístico (MARTELOTTA, 2011), a pesquisa funcionalista tem como ponto de partida dados empíricos de uso real da língua em textos falados, escritos e/ou multimodais.

Entre os princípios e categorias analíticas da Linguística Funcional, utilizamos, nesta pesquisa, os princípios de iconicidade, marcação e a noção de informatividade. Esses conceitos são importantes para subsidiar a proposta de tratamento das orações adjetivas em sala de aula, principalmente para discutirmos aspectos relativos às diferentes formas de organização da adjetiva (padrão, cortadora, copiadora) e para a distinção das adjetivas com base na sua relação com o Sintagma Nominal (SN) antecedente.

O princípio de iconicidade é definido como a correlação motivada entre forma e função, com base na ideia de que a estrutura linguística reflete, de algum modo, a estrutura da experiência (GIVÓN, 1984), compreendendo três subprincípios. O da quantidade relaciona o volume e a previsibilidade de informação à quantidade de forma para codificá-la. O subprincípio da integração correlaciona a distância linear entre os elementos à distância conceptual entre as ideias por eles representadas, isto é, o que está cognitivamente próximo tende a ser codificado de maneira mais integrada. O subprincípio da ordenação linear estabelece que os constituintes se ordenam, no tempo e no espaço, conforme pressões cognitivas. A iconicidade é, portanto, estimulada por questões de clareza e transparência, de modo a reduzir a opacidade entre a forma linguística e seu correlato semântico e/ou pragmático.

o princípio de marcação está relacionado à presença de uma propriedade nos membros em um par contrastivo, cuja ausência caracteriza o elemento não marcado (FURTADO DA CUNHA; COSTA; 
CEZARIO, 2015). Existem três critérios principais que podem ser usados para distinguir uma categoria marcada de uma não marcada, num contraste binário (GIVÓN, 1990). São eles: a) Complexidade estrutural - a categoria marcada tende a ser mais complexa (mais extensa) que a estrutura não marcada correspondente; b) Complexidade cognitiva - a estrutura marcada tende a ser mais complexa cognitivamente que a correspondente não marcada; c) Distribuição de frequência - a estrutura marcada normalmente é menos frequente que a estrutura não marcada.

A informatividade, por sua vez, diz respeito ao que os interlocutores compartilham, ou supõem compartilhar, na interação (FURTADO DA CUNHA; COSTA; CEZARIO, 2015). Prince (1981) classifica as entidades do discurso a partir da noção de conhecimento compartilhado, organizando-as em três grupos: (i) nova, quando é introduzida pela primeira vez no discurso; (ii) evocada ou velha, quando já tiver ocorrido no texto ou se estiver disponível na situação comunicativa; e (iii) inferível, quando é identificada por meio de um processo de inferência, partindo de informações dadas.

Conquanto o Funcionalismo norte-americano não tenha uma agenda voltada ao ensino de língua, alguns pesquisadores brasileiros, notadamente ligados ao grupo Discurso \& Gramática (D\&G), têm discutido a relação entre pressupostos funcionalistas e o ensino de Língua Portuguesa e/ou de gramática. Diversos trabalhos foram produzidos sobre diferentes aspectos gramaticais do Português, nos quais se discutem a natureza, o alcance e as implicações da Linguística Funcional para a prática pedagógica, a exemplo de Bispo (2007), Oliveira e Cezario (2007), Furtado da Cunha, Bispo e Silva (2014), Oliveira e Wilson (2015), Furtado da Cunha e Tavares (2016), entre outros.

Nessa direção, Furtado da Cunha, Bispo e Silva (2014, p. 84) ressaltam que "a proposta de ensino de língua numa vertente funcionalista objetiva trabalhar questões linguísticas com base em seus propósitos discursivo-pragmáticos, vinculados a práticas sociais situadas". Essa visão dialoga com a proposta dos PCN (BRASIL, 1998) de Língua Portuguesa, especialmente quanto ao preparo do aluno para que ele possa utilizar adequadamente a linguagem nas múltiplas demandas sociais. Também encontra eco na BNCC, segundo a qual

Os conhecimentos sobre a língua, as demais semioses e a norma-padrão não devem ser tomados como uma lista de conteúdos dissociados das práticas de linguagem, mas como propiciadores de reflexão a respeito do funcionamento da língua no contexto dessas práticas (BRASIL, 2018, p. 139). 
V. $10(2)$

1-21 maio-ago 2020

A visão funcionalista de ensino de língua materializa-se em atividades de análise e reflexão linguísticas, por meio das quais se aprimoram as capacidades de compreensão e expressão dos alunos, isto é, sua competência comunicativa (FURTADO DA CUNHA; BISPO; SILVA, 2014).

O trabalho analítico e reflexivo sobre a língua, segundo registram Oliveira e Wilson (2008), deve tomar como ponto de partida a observação das estruturas mais regulares verificadas no desempenho discursivo. Assim, o que se propõe é um trabalho que parta da investigação das estratégias recorrentes de expressão linguística, de modo a explicitar os princípios que regulam tais estratégias e que permitem a adequada interação entre os falantes da língua. Novamente, destacamos a correspondência da perspectiva funcionalista com as orientações curriculares, nas quais encontramos

Assume-se, na BNCC de Língua Portuguesa, uma perspectiva de progressão de conhecimentos que vai das regularidades às irregularidades e dos usos mais frequentes e simples aos menos habituais e mais complexos (BRASIL, 2018, p. 139).

Dessa forma, a orientação para o trabalho do professor, diferentemente da abordagem tradicional, não seria calcada na prescrição normativa, mas na observação das regularidades atestadas nas diversas situações sociointeracionais de uso da língua.

\section{Contextualização e caracterização da proposta didática}

A pesquisa aqui reportada foi desenvolvida em duas turmas do $9^{\circ}$ ano do Ensino Fundamental da Escola Estadual União do Povo de Cidade Nova, localizada na cidade de Natal/RN. Envolveu uma proposta didática para abordagem funcionalista da oração adjetiva na turma participante (turma A) e o tratamento tradicional desse tópico gramatical na turma de controle (turma B). Os sujeitos da pesquisa ${ }^{1}$ são 43 alunos das duas turmas selecionadas, sendo 20 da turma A e 23 da turma B, além da professora-pesquisadora. A consideração de uma turma de controle pautou-se na necessidade de proceder à comparação entre o desempenho de cada uma delas, de forma a tornar viável aferir a eficácia, ou não, do viés funcionalista aplicado ao tratamento das adjetivas em sala de aula.

\footnotetext{
${ }^{1}$ Esta pesquisa foi aprovada pelo Comitê de Ética em Pesquisa da Universidade Federal do Rio Grande do Norte por meio do parecer 2.890.714. São considerados sujeitos da pesquisa os alunos cujos responsáveis autorizaram sua participação por meio do termo de consentimento e que realizaram as atividades inicial e final.
} 
O trabalho realizado é de natureza quali-quantitativa com caráter interpretativista, visto que, além de mensurar dados relativos às respostas dos alunos às atividades propostas, nós as analisamos levando em conta a interação de aspectos sintáticos, semânticos, discursivos e pragmáticos do fenômeno sob estudo.

A estruturação didática das aulas ministradas orientou-se na discussão de Libâneo (2013) quanto à organização das tarefas do processo de ensino, as chamadas etapas ou passos didáticos. Seguindo essa orientação, a sequência foi organizada em quatro etapas, apresentadas no quadro 1, e compôs-se de 10 aulas de 50 minutos na turma A e de 08 aulas na turma B, todas ministradas no período de 6 a 24 de maio de 2019 .

Quadro 1 - Caracterização geral das etapas da sequência de aulas

\begin{tabular}{|c|c|c|c|}
\hline ETAPA & $\begin{array}{l}\text { TURMA/ } \\
\text { DURACẼ̃o }\end{array}$ & DESCRIÇÃO & OBJETIVO(S) \\
\hline $\begin{array}{l}\text { Diagnóstico e } \\
\text { introdução do } \\
\text { conteúdo }\end{array}$ & $\begin{array}{c}\mathrm{A} / \mathrm{B} \\
2 \text { aulas }\end{array}$ & $\begin{array}{c}\text { Atividade } \\
\text { diagnóstica inicial } \\
\text { para sondagem } \\
\text { e introdução ao } \\
\text { conteúdo. }\end{array}$ & $\begin{array}{c}\text { Verificar conhecimentos } \\
\text { prévios dos alunos acerca } \\
\text { de adjetivo e oração } \\
\text { adjetiva; introduzir } \\
\text { o estudo das orações } \\
\text { adjetivas. }\end{array}$ \\
\hline \multirow[t]{2}{*}{$\begin{array}{l}\text { Tratamento } \\
\text { didático do } \\
\text { conteúdo }\end{array}$} & $\begin{array}{c}\text { A } \\
3 \text { aulas }\end{array}$ & $\begin{array}{c}\text { Estudo das orações } \\
\text { adjetivas por } \\
\text { meio da resolução } \\
\text { de exercícios, } \\
\text { contemplando } \\
\text { formas canônicas } \\
\text { e não canônicas e } \\
\text { fatores semântico- } \\
\text { pragmáticos } \\
\text { envolvidos no uso } \\
\text { desse tipo oracional. }\end{array}$ & $\begin{array}{l}\text { Apresentar o conteúdo, } \\
\text { de forma gradativa, } \\
\text { a partir da análise de } \\
\text { textos autênticos; discutir } \\
\text { questões semântico-- } \\
\text { pragmáticas implicadas } \\
\text { no uso das adjetivas. }\end{array}$ \\
\hline & $\begin{array}{c}\text { B } \\
2 \text { aulas }\end{array}$ & $\begin{array}{c}\text { Apresentação do } \\
\text { conceito de oração } \\
\text { adjetiva e de sua } \\
\text { classificação. }\end{array}$ & $\begin{array}{l}\text { Apresentar o conteúdo de } \\
\text { modo sistematizado. }\end{array}$ \\
\hline \multirow[t]{2}{*}{$\begin{array}{l}\text { Consolidação } \\
\text { dos } \\
\text { conhecimentos } \\
\text { e habilidades }\end{array}$} & $\begin{array}{c}\text { A } \\
3 \text { aulas }\end{array}$ & $\begin{array}{l}\text { Sistematizaçã̃o da } \\
\text { caracterização da } \\
\text { oração adjetiva, } \\
\text { de suas formas de } \\
\text { organização e de } \\
\text { sua classificação. } \\
\text { Trabalho em } \\
\text { pequenos grupos } \\
\text { para socialização do } \\
\text { aprendizado. }\end{array}$ & $\begin{array}{c}\text { Apresentar o conteúdo } \\
\text { de modo sistematizado. } \\
\text { Correlacionar o uso } \\
\text { das adjetivas a fatores } \\
\text { semântico-pragmáticos. } \\
\text { Estimular o engajamento } \\
\text { dos alunos no processo } \\
\text { de aprendizagem do } \\
\text { conteúdo. }\end{array}$ \\
\hline & $\begin{array}{c}\text { B } \\
2 \text { aulas }\end{array}$ & $\begin{array}{l}\text { Resolução e correção } \\
\text { de exercício de } \\
\text { fixação do conteúdo. }\end{array}$ & $\begin{array}{l}\text { Fixar o conteúdo } \\
\text { estudado. }\end{array}$ \\
\hline
\end{tabular}


V. $10(2)$

1-21

maio-ago

2020

\begin{tabular}{|c|c|c|c|}
\hline $\begin{array}{l}\text { Avaliação dos } \\
\text { resultados }\end{array}$ & $\begin{array}{c}\text { A/B } \\
2 \text { aulas }\end{array}$ & $\begin{array}{l}\text { Aplicação de } \\
\text { atividade final. }\end{array}$ & $\begin{array}{l}\text { Verificar a aprendizagem } \\
\text { dos alunos em relação } \\
\text { ao conteúdo. Cotejar o } \\
\text { desempenho de cada } \\
\text { turma e correlacioná-lo } \\
\text { ao tipo de abordagem } \\
\text { implementada. }\end{array}$ \\
\hline
\end{tabular}

Fonte: autoria própria.

\section{Aplicação da proposta e discussão dos resultados}

Na primeira parte desta seção, sintetizamos as três etapas iniciais da proposta didática, com breve descrição de cada uma delas e de sua aplicação. Na segunda, fazemos uma análise quali-quantitativa do desempenho dos alunos na atividade final, associando-o ao tipo de abordagem e ao conteúdo implementado em cada turma.

Diagnóstico das turmas e abordagem do conteúdo

Considerando a visão funcionalista de tratamento de fenômenos linguísticos, propusemos, na atividade diagnóstica, aplicada nas duas turmas, uma reflexão sobre aspectos semânticos e pragmáticos relacionados ao uso da oração adjetiva. Foram considerados: i) possível correspondência entre adjetivo e oração adjetiva; ii) modificação por meio da oração adjetiva: restrição e comentário; iii) termo antecedente a que a adjetiva se vincula; iv) uso de pronomes relativos; v) articulação de porções textuais por meio da oração adjetiva.

As questões que compuseram a atividade basearam-se em textos autênticos representantes de gêneros distintos, previstos na BNCC, a exemplo de notícia, tirinha, resenha, canção etc. A opção pelo uso de variadas configurações textuais atende ao viés funcionalista de estudo da linguagem, no sentido de permitir detectar usos linguísticos em contextos múltiplos.

A relação entre adjetivo e oração adjetiva foi trabalhada a partir de uma notícia, particularmente de seu título, em suas versões original (Brumadinho: parentes de vítimas mortas em pousada pedem indenização de R\$ 40 milhões $^{2}$ ) e modificada (Brumadinho: parentes de vítimas que morreram em pousada pedem indenização de $\mathrm{R} \$ 40$ milhões). Indagamos semelhanças e/ou diferenças percebidas pelos alunos quanto ao uso dessas formas. O objetivo era introduzir a reflexão

2 Disponível em: https://g1.globo.com/mg/minas-gerais/noticia/2019/04/22/ brumadinho-parentes-de-vitimas-mortas-em-pousada-pedem-indenizacao-de-r40-milhoes.ghtml. Acesso em: 22 abr. 2019. 
sobre o papel modificador da oração adjetiva, correlacionando-a ao adjetivo, de modo que os alunos pudessem perceber pontos de aproximação ou de diferença entre as duas categorias.

Reformulamos também um trecho de uma resenha crítica para, a partir da comparação com o texto original, abordarmos o papel coesivo da adjetiva para a concisão textual. A versão original continha pronomes relativos que, na versão modificada, foram substituídos pelos substantivos antecedentes ${ }^{3}$.

Ainda a partir da resenha, tratamos da relação entre a oração adjetiva e o SN a que ela se vincula, indagando o tipo de informação acrescentada pela adjetiva com base no contexto, se era indispensável ao entendimento do antecedente, de modo a restringi-lo, ou se adicionava uma informação pertinente, um comentário. Dessa forma, introduzimos a reflexão sobre aspectos semânticos e pragmáticos da adjetiva e de seu antecedente.

O pronome relativo também foi abordado nessa atividade a partir da leitura de uma tirinha, na qual havia duas ocorrências de adjetivas introduzidas pelo relativo que. Solicitamos que os estudantes indicassem: i) a possibilidade de esse elemento ser substituído e, em caso positivo, por qual(is) termo(s); ii) se essa substituição acarretaria alteração semântica. O objetivo era verificar o conhecimento dos alunos acerca de outros pronomes relativos, bem como estimular a reflexão sobre formas alternativas de expressão de mesmo conteúdo proposicional. Nessa direção, a atividade guarda consonância com o entendimento funcionalista e com as orientações curriculares nacionais, no sentido de oportunizar ao aprendiz o contato com diferentes possibilidades de usos da língua.

Por fim, solicitamos a produção de uma resenha ${ }^{4}$ com a finalidade de propiciar um contexto para o uso de orações adjetivas pelos alunos. Contabilizamos a ocorrência de 90 orações adjetivas, num universo de 32 textos, sendo 71 relativas padrão, de sujeito e objeto direto, 17 cortadoras e duas copiadoras. A ausência de relativa padrão em funções preposicionadas (complemento relativo, objeto indireto e adjunto adverbial) corrobora os achados de Bispo (2009) quanto ao predomínio da cortadora em ambientes preposicionados. Essas ocorrências serviram de mote, em etapa posterior, para o tratamento de estratégias de relativização na turma participante.

\footnotetext{
${ }_{3}^{3}$ Não transcrevemos aqui as questões da atividade diagnóstica por não ser necessário aos propósitos do artigo.

${ }^{4}$ A opção por esse gênero textual deveu-se ao fato de ele constar do conjunto de gêneros previstos para serem estudados no $9^{\circ}$ ano.
} 
V. $10(2)$

1-21 maio-ago 2020
As respostas dos alunos à atividade inicial foram importantes para introduzir a discussão acerca das orações adjetivas na turma A, nas aulas seguintes, e, em particular, para o tratamento de aspectos formais e funcionais a elas relacionados ${ }^{5}$. Considerando o que orienta a abordagem funcional, possibilitamos um olhar para as estruturas linguísticas de um ponto de vista mais complexo, que vai além dos aspectos morfossintáticos, levando em conta também os propósitos comunicativos atinentes ao processo de interação verbal (FURTADO DA CUNHA; BISPO; SILVA, 2014).

Na segunda etapa, tivemos procedimentos distintos para cada turma. Na turma A, iniciamos o estudo da adjetiva em funcionamento no texto, levando os alunos a perceberem as intenções comunicativas relacionadas às escolhas do falante, por meio da resolução de uma atividade em pequenos grupos. Na turma $B$, foram apresentados e explicados o conceito e a classificação das adjetivas por meio da exposição oral da professora-pesquisadora e registro do conteúdo pelos alunos.

As questões da atividade na turma participante contemplavam: relação entre adjetivo e oração adjetiva potencialmente correspondente; papel semântico e discursivo das adjetivas no texto; uso das estratégias de relativização em diferentes situações de monitoramento da língua e papel coesivo da adjetiva no texto. Partimos do emprego das adjetivas em textos produzidos em situações reais de fala/escrita, de forma a proporcionar reflexão sobre seus usos, conforme orienta a perspectiva funcionalista. Somente após esse contato, foram apresentados, na etapa seguinte, conceitos relacionados à nomenclatura e à classificação das adjetivas.

De início, abordamos a relação semântica entre adjetivo e oração adjetiva e os efeitos de sentido relacionados a esses usos a partir de uma notícia, em suas versões original e modificada, transcritas a seguir:

(1) PM prende suspeitos com equipamento que bloqueia travamento de carros em shopping de Natal. ${ }^{6}$

(2) PM prende suspeitos com equipamento bloqueador de travamento de carros em shopping de Natal.

\footnotetext{
5 Em função dos propósitos deste artigo, não detalhamos as respostas dadas pelos alunos nessa etapa da intervenção.

6 Disponível em: https://g1.globo.com/rn/rio-grande-do-norte/noticia/2019/04/15/ pm-prende-suspeitos-com-equipamento-que-bloqueia-travamento-de-carrosem-shopping-de-natal.ghtml. Acesso em: 22 abr. 2019.
} 
O cotejo entre a oração adjetiva e o adjetivo potencialmente correlato assentou-se nos princípios de marcação e de iconicidade (GIVÓN, 1984) e na consideração de propósitos comunicativos implicados. A estrutura oracional é marcada em relação ao potencial adjetivo equivalente por apresentar mais complexidade de forma e, supostamente, mais complexidade cognitiva. À maior extensão da oração adjetiva em relação ao adjetivo virtualmente correlato corresponde mais conteúdo (envolve, por exemplo, informações de tempo e modo presentes no verbo), daí ser mais icônica. Assim, a escolha pelo adjetivo, ou pela oração adjetiva, pode atender a uma demanda cognitiva (de menor custo de elaboração e/ou de processamento) ou comunicativa, em termos de clareza, expressividade ou do que se pretende enfatizar: a propriedade do nome modificado (bloqueador) ou a ação que por meio dele se realiza (bloquear).

Para o tratamento das estratégias de relativização, utilizamos a tirinha a seguir, na qual o personagem comenta situações informais cotidianas.

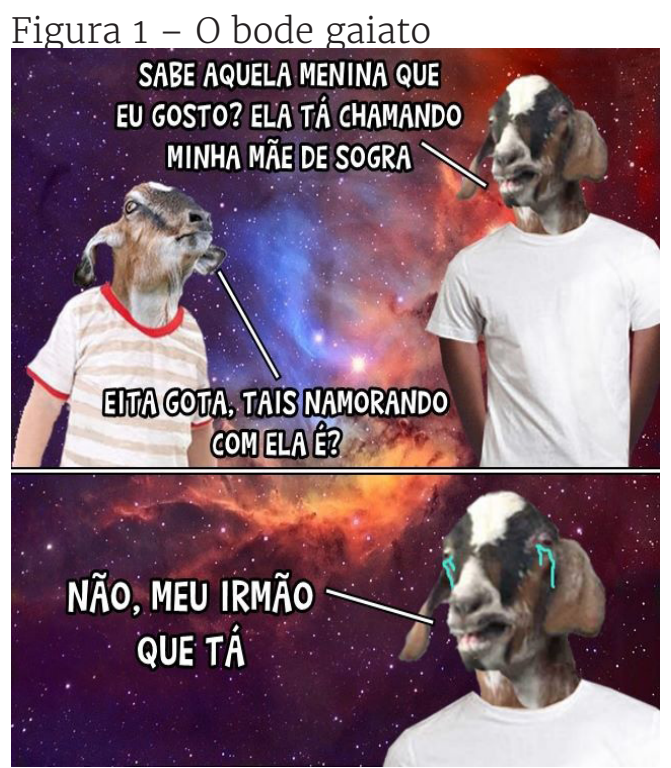

Fonte: Facebook ${ }^{7}$.

Considerando um trabalho calcado em viés funcionalista e em orientações curriculares oficiais (BRASIL, 1998, 2018), apresentamos diferentes possibilidades de estruturar a oração adjetiva, associadas ao mesmo conteúdo proposicional. O objetivo era verificar se os alunos reconhecem essas formas, fazê-los refletir se esses usos são comuns e relacionar tais usos à situação comunicativa. Para isso, apresentamos

${ }_{7}$ Disponível em: https://www.facebook.com/BodeGaiato. Acesso em: 20 mar. 2018. 
V. $10(2)$

1-21

maio-ago

2020

a adjetiva cortadora, presente na primeira fala da tirinha, nas formas padrão e copiadora, explicitadas, respectivamente, a seguir:

\section{(3) Conhece aquela menina de quem eu gosto? \\ (4) Sabe aquela menina que eu gosto dela?}

Questionamos aos alunos qual seria a maneira mais adequada para a situação original da tirinha e para a situação hipotética de uma entrevista de emprego ${ }^{8}$. De modo geral, eles identificaram a cortadora como adequada à tira e associaram a adjetiva com preposição antes do relativo à situação de entrevista. Vários alunos, porém, expressaram estranhamento em relação à copiadora, em (4), indicando desconhecer essa estratégia e achar pouco provável esse tipo de ocorrência. O alegado desconhecimento dessa forma ou o pouco uso mencionado pelos alunos reforça o que já foi referido em alguns estudos, tais como os de Bispo (2007, 2009 e 2014) a respeito do estigma associado à forma copiadora, o que, provavelmente, concorre para que essa estratégia seja evitada.

O exame da estrutura de cada uma das estratégias também revelou dificuldade, por parte dos alunos, quanto à organização da adjetiva com preposição antes do relativo (relativa padrão preposicionada (RPP), nos termos de BISPO (2009, 2014)). Conforme discutido em Bispo (2018), o uso de preposição antes do pronome relativo implica a realização, por parte do falante/escrevente, de operações sintáticas internas à oração adjetiva, no sentido de reconhecer que essa preposição é requerida por um elemento verbal ou nominal dela distanciado, qual é a preposição a ser empregada e que posição ela ocupará na cláusula. Essas operações, naturalmente, são bastante complexas para alunos do ensino fundamental. Considerando a pouca (ou nenhuma) familiaridade dos alunos com a RPP, foi discutido com a turma o uso de preposições antes do relativo. Para tanto, foram consideradas as seguintes questões: i) que elemento(s) demanda(m) preposição, ii) qual a preposição demandada e iii) que posição esse elemento gramatical ocupa na oração adjetiva.

A discussão sobre diferentes formas de organização da oração adjetiva foi profícua, uma vez que contou com o engajamento dos alunos, a quem foi oportunizado conhecer essas formas e refletir sobre adequação e motivações de uso. No caso particular da atividade

\footnotetext{
${ }^{8}$ Reconhecemos que, numa entrevista real de emprego, dificilmente fossem abordadas questões de foro íntimo, como namoro. A hipótese aventada deu-se apenas para o entendimento pelo aluno de tratar-se de situação formal.
} 
desenvolvida, cabe mencionar que o trabalho com textos produzidos em situações menos monitoradas (a tirinha, por exemplo), conforme ressaltam Furtado da Cunha, Bispo e Silva (2014), pode acercar os alunos do conteúdo sistematizado de que se ocupa a escola. Isso porque, devido ao menor grau de formalidade implicado, promove uma aproximação com a variedade linguística por eles utilizada.

A terceira etapa, na turma $B$, foi dedicada à realização de exercício de fixação do conteúdo já apresentado e incluía substituição de adjetivos por orações potencialmente equivalentes, união de períodos simples em período composto e classificação das adjetivas. Na turma A, porém, foi introduzido o estudo do conteúdo sistematizado. Compilamos, a respeito da adjetiva, os conceitos necessários para uma reflexão mais ampla dessa categoria gramatical e entregamos o material impresso aos alunos para que pudessem associar o conteúdo ao que foi discutido durante a resolução da atividade.

Relativamente à classificação binária restritiva vs. explicativa, discutimos, combase em estudos como os de Oliveira(2001), Souza (2009) e Lopes (2019), que essas orações atendem a propósitos comunicativos distintos. Por meio de ocorrências extraídas de situações reais de uso da língua, mostramos o papel delimitador da oração restritiva, de identificar o antecedente dentro de um conjunto maior de possibilidades; e o papel textual-discursivo da adjetiva explicativa, de comentário/ justificativa/ argumentação, como evidenciado por Leitão (2009) e Lopes (2019). Além disso, propiciamos uma reflexão sobre a pontuação, comumente associada à distinção dessas formas, ressaltando que ela é resultante do processo de elaboração da adjetiva, conforme a intenção do falante, não simplesmente uma marca opositiva entre restrição e explicação.

Etapa final: caracterização, aplicação e resultados

As duas turmas realizaram a atividade final, cujas questões iniciais se referiam a uma canção ${ }^{9}$ e a uma matéria jornalística ${ }^{10}$. Buscamos verificar a percepção dos alunos quanto aos usos do pronome relativo em um verso da canção (5), o qual foi retomado e modificado no texto jornalístico (6), mostrados a seguir.

\footnotetext{
${ }_{9}$ Rap do Silva, de Bob Rum. Disponível em: https://www.vagalume.com.br/bob-rum/ rap-do-silva.html. Acesso em: 05 out. 2018.

10 Disponível em: <https://oglobo.globo.com/rio/bairros/autor-do-rap-do-silvabob-rum-celebra-20-anos-de-carreira-com-apresentacao-no-reveillon-dopiscinao-de-ramos-14904757> Acesso em: 05 out. 2018.
} 
V. 10 (2)

1-21

maio-ago

2020
(5) Era só mais um Silva que a estrela não brilha

(6) Só mais um Silva cuja estrela não brilha

Solicitamos que os alunos explicassem a que, possivelmente, se devia a alteração do pronome relativo de (5) para (6), considerando a intenção comunicativa e as características dos dois textos. Dos 20 alunos que realizaram a atividade na turma A, 16 (80\%) correlacionaram o pronome cujo a usos mais monitorados, como apresentado em (7) e (8), enquanto apenas seis alunos da turma B (26\%), dos 23, fizeram essa relação, como ilustrado em (9). Esses números mostram desempenho satisfatório da turma A quanto à reflexão sobre as possíveis motivações para escolhas léxico-gramaticais, particularmente no tocante a uso de pronomes relativos, considerando características dos gêneros textuais envolvidos.

(7) "O cuja foi posto para tornar mais formal, pois esta indo para um jornal." "11 (Aluno 12 $\mathrm{A}^{12}$ )

(8) "Acho que as modificações não mudam o sentido da frase. A primeira se torna mais utilizada (comum) e a $2^{\mathrm{a}}$ se torna mais formal." (Aluno 20A)

(9) "A modificação do 'que' a 'cuja' é feita por causa do tipo de comunicação, sendo no texto 1 a letra da música e o texto 2 num jornal, fazendo ter as palavras um sinônimo, um sentido mais formal." (Aluno 3B)

Os alunos também foram instados a analisar orações adjetivas à luz da distinção restritiva vs. explicativa, considerando o papel semântico-pragmático a elas relacionado. Para tanto, foram tomados os seguintes versos da canção referida:

(10) Porque tem muito amigo que vai pro baile dançar (11) E o pobre do nosso amigo que foi pro baile curtir

A atividade solicitava aos alunos que indicassem: i) o referente do antecedente do relativo nas duas situações e ii) a classificação

\footnotetext{
${ }^{11}$ Transcrevemos as respostas dos alunos tais quais foram redigidas, daí, por exemplo, a ausência de acentos.

${ }^{12}$ Os alunos foram identificados por algarismos indo-arábicos; e as turmas, pelas letras A/B.
} 
das orações adjetivas destacadas, com justificativa, considerando o papel de especificação ou de comentário em relação ao nome a que se vinculam. Essa questão envolvia, primeiramente, a identificação do referente do antecedente do relativo e a percepção da informatividade desse elemento, o que implicava correlacionar muito amigo a um grupo não específico, e o nosso amigo ao personagem referido na canção. Ou seja, os antecedentes remetem a entidades do discurso com estatutos informacionais distintos (novo e dado, respectivamente), nos termos de Prince (1981). Dessa percepção, resultava a classificação da adjetiva em restritiva ou explicativa com base no papel que desempenha em relação ao termo a que se vincula.

Considerando as respostas dadas a essa questão, verificamos que $13(65 \%)$ alunos da turma A e $6(26 \%)$ da turma B identificaram adequadamente os dois referentes. Quanto à classificação das adjetivas, 11 alunos de cada turma identificaram corretamente a restritiva e a explicativa, mas desses apenas alunos da turma A (6, no caso) justificaram devidamente a classificação apresentada. Vejamos algumas respostas:

(12) "A primeira se refere a todos que vão, aos colegas da vida. A segunda é o amigo intimo, o amigo que ele fala na canção." (Aluno 12A)

(13) "Na primeira frase se refere aos amigos que o sujeito tem. Na segunda se refere ao único amigo, que na minha perspectiva, é o sujeito da frase anterior." (Aluno 14A)

(14) " $\mathrm{i}$ - se refere as pessoas que vão para o baile dançar. Ii se refere ao Silva." (Aluno 7B)

(15) " $\mathrm{i}$ - se refere aos outros amigos que iam pro baile ii - se refere ao personagem principal da musica" (Aluno 21B)

O melhor desempenho da turma A pode ser explicado pelo tipo de abordagem dado ao conteúdo, com foco em aspectos semânticopragmáticos tanto do SN antecedente quanto da oração adjetiva.

Ainda voltada à tipologia das adjetivas e, em particular, a relação com o uso de vírgula, uma questão de múltipla escolha instava os alunos a identificarem a assertiva adequada a respeito do seguinte trecho, extraído da matéria jornalística já referida. O foco era indicar se a adjetiva destacada deveria ou não ser separada por vírgula e o porquê disso. 
V. $10(2)$

1-21

maio-ago

2020

(16) "Aos 45 anos, esse funkeiro que começou a frequentar os bailes apenas para dançar, há muito já deixou de ser 'só mais um Silva cuja estrela não brilha".

A questão implicava avaliar o papel da adjetiva em relação ao termo antecedente. Na turma A, 13 alunos (65\%) assinalaram a alternativa correta, enquanto na B foram oito (35\%).

Quando, porém, foi solicitado identificar orações adjetivas presentes num texto, os alunos das duas turmas não conseguiram. Isso provavelmente se deve à pouca familiaridade com a análise de estruturas oracionais complexas e, em particular, com as adjetivas. Essa pouca familiaridade, por sua vez, relaciona-se ao fato de que os alunos iniciaram o estudo do período complexo no $9^{\circ}$ ano e ao tempo exíguo reservado para o trabalho com as adjetivas.

Também correlacionamos o uso da oração adjetiva à construção do humor no texto, mais especificamente a que aparece no último quadrinho da tirinha a seguir.

Figura 2 - Oração adjetiva e construção de sentido
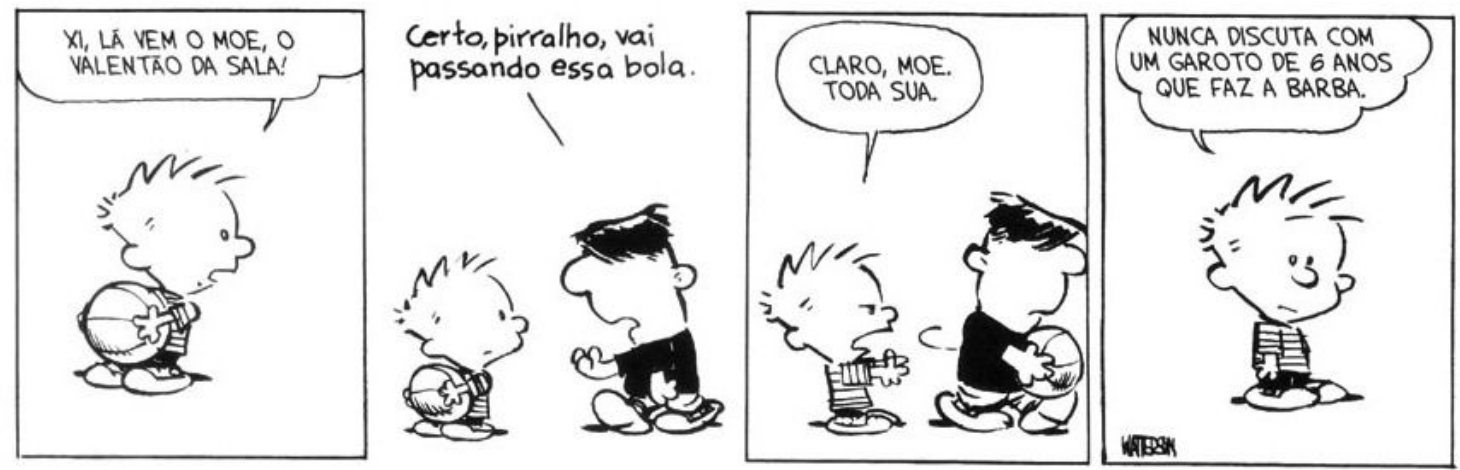

Fonte: Revista Nova Escola online ${ }^{13}$.

Solicitamos que os alunos indicassem o papel da adjetiva para a construção do efeito de humor da tirinha. Para tanto, eles precisavam perceber que, ao caracterizar o personagem como um garoto de 6 anos que faz a barba, o autor reforça a ideia, apresentada no primeiro quadrinho, de que o Moe é um "valentão", um garoto de comportamento agressivo, dada a característica incompatível com sua idade. Na turma A, 11 alunos (55\%) perceberam a contribuição da adjetiva para o texto, como se pode ver em (17). Na turma B, oito alunos (35\%) interpretaram adequadamente a tirinha, como ilustrado em (18).

13 Disponível em: https://novaescola.org.br/conteudo/3621/calvin-e-seus-amigos. Acesso em: 10 jun. 2018. 
(17) "Porque é uma criança com características adultas." (Aluno 5A)

(18) "Porque é uma característica incomum para um garoto de 6 anos por isso é usada para fazer humor." (Aluno 23B)

Conforme os quantitativos aferidos pelas respostas dadas, podemos observar um desempenho melhor da turma A em relação à de controle. Mais uma vez, creditamos essa diferença ao tipo de abordagem do conteúdo em cada turma.

A atividade final também abordou as estratégias de relativização (padrão preposicionada, cortadora e copiadora) partindo de trechos extraídos do Corpus D\&G Natal (FURTADO DA CUNHA, 1998). O primeiro deles era de uma narrativa recontada falada, produzida por informante do Ensino Médio, no qual destacamos duas relativas cortadoras. O segundo foi retirado de uma narrativa recontada escrita por um informante do Ensino Fundamental e apresentava uma RPP em destaque. Foram apresentadas duas outras versões para cada oração adjetiva, de modo a ilustrar as três estratégias de relativização, como vemos a seguir:

Quadro 2 - Estratégias de relativização

\begin{tabular}{|c|c|c|c|}
\hline & Trecho original & Primeira adaptação & Segunda adaptação \\
\hline Texto 1 & $\begin{array}{l}\text {... e tem a cadeira de } \\
\text { balanço do meu tio } \\
\ldots \text { né... que ele gosta } \\
\text { também ... tem a mesa } \\
\ldots \text { tem ... o armário da } \\
\text { minha tia ... que ela } \\
\text { ((riso)) cuida muito. }\end{array}$ & $\begin{array}{l}\text {... e tem a cadeira de } \\
\text { balanço do meu tio ... né } \\
\text { que ele gosta também } \\
\text { dela... tem a mesa ... tem } \\
\ldots \text { o armário da minha } \\
\text { tia ... que ela ((riso)) } \\
\text { cuida muito dele. }\end{array}$ & $\begin{array}{l}\text {... e tem a cadeira } \\
\text { de balanço do meu } \\
\text { tio ... né ... da qual } \\
\text { ele gosta também } \\
\ldots \text { tem a mesa ... } \\
\text { tem ... o armário } \\
\text { da minha tia ... do } \\
\text { qual ela ((riso)) } \\
\text { cuida muito. }\end{array}$ \\
\hline Texto 2 & $\begin{array}{l}\text { Então, um dia Jó teve um } \\
\text { sonho, no qual o Diabo } \\
\text { lhe falava que ele iria } \\
\text { perder sua fé em Deus... }\end{array}$ & $\begin{array}{l}\text { Então, um dia Jó teve um } \\
\text { sonho, que o Diabo lhe } \\
\text { falava que ele iria perder } \\
\text { sua fé em Deus... }\end{array}$ & $\begin{array}{l}\text { Então, um dia Jó } \\
\text { teve um sonho, que } \\
\text { o Diabo lhe falava } \\
\text { no sonho que ele } \\
\text { iria perder sua fé } \\
\text { em Deus... }\end{array}$ \\
\hline
\end{tabular}

Fonte: adaptado de Furtado da Cunha (1998).

Foi indagado aos alunos que modificação estrutural ocorreu nas adaptações feitas e se houve (e qual) alteração semântica. Quanto às mudanças estruturais, 13 (65\%) alunos da turma A apontaram alterações, enquanto na turma B foram 12 (52\%). Os demais alunos nada responderam a esse respeito. Em relação à outra indagação, a maioria 
V. $10(2)$

1-21

maio-ago

2020
(17 da turma A; 16 da turma B) não fez referência à possível mudança semântica. Os comentários da turma A contemplaram aspectos relativos à formalidade dos textos, ainda que tenham mencionado apenas um deles, no caso, o texto 1, como pode ser visto em (19); já os alunos da turma B não fizeram esse tipo de relação, a exemplo de (20).

(19) "Não teve alteração no sentido, mas a primeira adaptação ficou mais informal e a terceira ficou formal." (Aluno 14A)

(20)"Sim, quase não dá pra perceber nada, pois está tudo do mesmo jeito, mais só muda algumas palavras e não dá nem pra perceber tanto." (Aluno 10B)

Os alunos também foram questionados acerca da adequação das configurações da adjetiva para cada trecho. Assim, foi indagado qual das três formas era mais adequada nas duas situações comunicativas. Na turma A, três alunos correlacionaram apropriadamente as estratégias de relativização aos dois trechos, e na turma $\mathrm{B}$, um aluno; outros três estudantes da turma A e três da turma B fizeram a correlação apropriada a apenas um dos textos. Eles associaram a cortadora e/ou copiadora ao texto 1 e a forma padrão ao 2, como exemplificado de (21) a (23).

(21) "i) a primeira adaptação é mais adequada para língua falada. ii) texto original é mais adequado para a língua escrita." (Aluno 5A)

(22) "No texto 1 a primeira adaptação seria a mais correta para a linguagem falada e no texto 2 a mais apropriada para a língua escrita seria o original." (Aluno 7A)

(23) "1 - O texto original, pois não é muito formal, e geralmente fala informalmente. 2 - A primeira adaptação (Aluno 22B)

O baixo índice de acertos das turmas, em particular da participante, provavelmente se deve à pouca abordagem, em aulas de Língua Portuguesa, de usos linguísticos associados a situações comunicativas distintas. No que diz respeito especificamente às estratégias de relativização, destacamos que: i) na turma $B$, elas não foram trabalhadas; ii) na turma $\mathrm{A}$, o tempo destinado à discussão foi exíguo. Entendemos, assim, ser necessário um trabalho contínuo calcado na multiplicidade de usos da língua, correlacionados a diferentes 
situações de interação verbal e a propósitos comunicativos diversos. Relativamente às formas de organização da oração adjetiva, cabe um trabalho mais detido, o que implica maior tempo disponível.

De forma resumida, o cotejo do desempenho na atividade final das duas turmas revela que a turma participante apresentou melhor compreensão das adjetivas, em termos de: i) formas diferentes de organização desse tipo oracional, ii) associação dessas formas a contextos interacionais distintos, ainda que limitados à modalidade da língua, iii) papel semântico-pragmático em relação ao antecedente, iv) distinção entre restritiva e explicativa e v) escolha de pronome em função do nível de monitoramento implicado em determinada situação comunicativa.

\section{Considerações finais}

A intervenção aqui reportada envolveu duas turmas de $9^{\circ}$ ano, uma participante, outra de controle. A ideia básica consistiu em verificar efeitos da aplicação de uma proposta pedagógica de ensino de gramática assentada em premissas funcionalistas. Mais particularmente, em pontos de interseção entre tais premissas e as orientações para o ensino de Língua Portuguesa consubstanciadas nos PCN (BRASIL, 1998) e na BNCC (BRASIL, 2018).

O desenvolvimento da intervenção mostrou que a turma participante apresentou, em termos gerais, melhor aproveitamento. Tal resultado foi constatado tanto no engajamento/participação dos alunos durante as etapas da intervenção quanto no desempenho de atividades realizadas. Conforme descrito na seção anterior, o desempenho da turma A aferido na etapa de avaliação foi mais satisfatório que o da turma B, ainda que com leve diferença para alguns aspectos, como é o caso das estratégias de relativização. Em outros quesitos, porém, essa diferença foi mais nítida, como no que tange à relação entre a adjetiva e o nome antecedente a que ela se vincula ou no que diz respeito ao uso de relativos em situações mais e menos monitoradas.

O trabalho realizado resultou positivo, também, por revelar a necessidade de ajustes, seja em função da realidade das turmas, seja em atendimento às bases teóricas que o sustentaram. Tais ajustes incluem o tempo destinado às atividades, a readequação de algumas questões dos exercícios e a seleção de textos. Esse fato é perfeitamente compreensível por, pelo menos, duas razões: i) o processo de aprendizagem envolve constante avaliação e aprimoramento e ii) não existe uma proposta de 
V. $10(2)$

1-21

maio-ago

2020

ensino funcionalista consolidada, o que implica que as incursões feitas têm longo caminho a percorrer. Não significa, contudo, o impedimento de que experiências implementadas sob essa abordagem logrem êxito.

Destacamos, por fim, que a principal contribuição da proposta aqui relatada consiste nos pressupostos teórico-metodológicos que a norteiam, no sentido de assumir uma estreita relação entre os usos linguísticos e os propósitos comunicativos a que servem, daí contemplar a língua em funcionamento. Tais pressupostos guardam consonância com as diretrizes oficiais para o ensino de Língua Portuguesa. A intervenção realizada pode, portanto, ser tomada como um caminho para a abordagem prática não apenas da oração adjetiva, mas também para o ensino de outros tópicos gramaticais.

\section{Referências}

BISPO, E. B. Oração adjetiva cortadora: análise de ocorrências e implicações para o ensino de português. Linguagem \& Ensino, v. 10, p. 163-186, 2007.

BISPO, E. B. Estratégias de relativização no português brasileiro e implicações para o ensino: o caso das cortadoras. Tese (Doutorado em Estudos da Linguagem) - Programa de Pós-Graduação em Estudos da Linguagem, Universidade Federal do Rio Grande do Norte, Natal, 2009.

BISPO, E. B. Orações relativas em perspectiva histórica: interface uso e cognição. Veredas, v. 18, n. 1, p. 222-235, 2014.

BISPO, E. B. Relativa restritiva em perspectiva construcional. Entrepalavras, v. 8, n. esp., p. 28-44, 2018.

BRASIL. Ministério da Educação: Secretaria de Educação Básica. Base Nacional Comum Curricular. Brasília/DF: MEC/SEB, 2018. Disponível em: http:// basenacionalcomum.mec.gov.br/images/BNCC_EI_EF_110518_versaofinal_ site.pdf. Acesso em: 20 mar. 19.

BRASIL. Ministério da Educação: Secretaria de Ensino Fundamental: Parâmetros Curriculares Nacionais: terceiro e quarto ciclos do ensino fundamental língua portuguesa. Brasília/DF: MEC/SEF, 1998.

CÂMARA, A. L. A oração relativa em português sob a perspectiva discursivofuncional: interface entre a descrição e o ensino. 2015. 177 f. Tese (Doutorado em Estudos Linguísticos) - Instituto de Biociências, Letras e Ciências Exatas, Universidade Estadual Júlio de Mesquita Filho (UNESP), São José do Rio Preto, 2015.

DU BOIS, J. W. Competing motivations. In: HAIMAN, J. (Ed.). Iconicity in syntax. Amsterdam: John Benjamins, 1985. p. 343-365.

FURTADO DA CUNHA, M. A. (org.). Corpus Discurso e Gramática - a língua falada e escrita na cidade do Natal. Natal: EDUFRN, 1998. 
FURTADO DA CUNHA. M. A.; COSTA, M. A.; CEZARIO, M. M. Pressupostos teóricos fundamentais. In: FURTADO DA CUNHA, M. A.; OLIVEIRA, M. R.; MARTELOTTA, M. E. (Orgs.) Linguística funcional: teoria e prática. São Paulo: Parábola Editorial, 2015. p. 21-47.

FURTADO DA CUNHA. M. A.; BISPO, E. B.; SILVA, J. R. Linguística Funcional Centrada no Uso e ensino de português. Gragoatá, n. 36, p. $80-104,2014$.

FURTADO DA CUNHA. M. A.; TAVARES, M. A. (Orgs.). Funcionalismo e ensino de gramática. Natal: EDUFRN, 2016.

GIVÓN, T. Syntax: a functional-typological introduction. Amsterdam: John Benjamins, 1984. V. I

GIVÓN, T. Syntax: a functional-typological introduction. Amsterdam: John Benjamins, 1990. V. II.

LEITÃO, R. J. Relativas explicativas: aspectos sintático-semânticos e textual-discursivos. Tese (Doutorado em Linguística) - Programa de Pós-Graduação em Linguística, Universidade Federal do Ceará, Fortaleza, 2009.

\section{LIBÂNEO, J. C. Didática. 2. ed. São Paulo: Cortez, 2013.}

LOPES, A. B. F. 0 papel das orações adjetivas na ancoragem de referentes nominais. Dissertação (Mestrado em Estudos da Linguagem) - Programa de Pós-Graduação em Estudos da Linguagem, Universidade Federal do Rio Grande do Norte, Natal, 2019.

MARTELOTTA. M. E. Mudança linguística: uma abordagem baseada no uso. São Paulo: Cortez, 2011.

OLIVEIRA, M. R. Orações adjetivas: uma abordagem funcional. In: PASSEGGI, L.; OLIVEIRA, M. S. (Orgs.). Linguística e educação: gramática, discurso e ensino. São Paulo: Terceira Margem, 2001. p. 77-90.

OLIVEIRA, M. R.; CEZARIO, M. M. PCN à luz do funcionalismo linguístico. Linguagem \& Ensino, n. 10, p. 87-108, 2007.

OLIVEIRA, M. R.; WILSON, V. Linguística e ensino. In: MARTELOTTA, M. E. (Org.). Manual de linguística. São Paulo: Contexto, 2008. p. 235-242.

OLIVEIRA, M. R.; WILSON, V. Linguística funcional aplicada ao ensino de português. In: FURTADO DA CUNHA, M. A.; OLIVEIRA, M. R.; MARTELOTTA, M. E. (Orgs.). Linguística funcional: teoria e prática. São Paulo: Parábola, 2015. p. 79-110.

PRINCE, E. F. Toward a taxonomy of given/new information. In: COLE, P. (Ed.). Radical Pragmatics. New York: Academic Press, 1981. p. 223-254.

SOUZA, E. S. de A. C. de. A interpretação das cláusulas relativas no português do Brasil: um estudo funcional. Tese (Doutorado em Língua Portuguesa) - Faculdade de Letras, Universidade Federal do Rio de Janeiro, Rio de Janeiro, 2009. 